\title{
The epidemiology of diabetes mellitus in the United Kingdom: The Yorkshire Regional Childhood Diabetes Register
}

\author{
A.Staines ${ }^{1}$, H.J.Bodansky ${ }^{2}$, H.E. B. Lilley ${ }^{1}$, C.Stephenson ${ }^{2}$, R.J.Q.McNally ${ }^{1}$, R. A. Cartwright ${ }^{1}$ \\ ${ }^{1}$ Leukaemia Research Fund Unit for Clinical Epidemiology, University of Leeds, Leeds, UK \\ ${ }^{2}$ Academic Unit of General Medicine, University of Leeds, Leeds General Infirmary, Leeds, UK
}

\begin{abstract}
Summary. A register of the incidence of Type 1 (insulin-dependent) diabetes mellitus in the Yorkshire region of the United Kingdom has been completed. A total of 1,490 subjects aged between 0 and 16 years were identified from 1978 to 1990 , giving an incidence of 13.7 per 100,000 (ages $0-14$ ) or 13.6 per 100,000 (ages 0-16), comparable to other recent studies in the United Kingdom. An age-period-cohort analysis shows evidence for a modest drift effect of $1.75 \%$ per year (95\% confidence interval 0.28 to $3.25 \%)$. There is a marked epidemic pattern with peaks at 4-year intervals. The age-incidence curve is similar to that reported elsewhere,
\end{abstract}

having peaks in early childhood and puberty. Girls have an earlier pubertal peak than boys. There is substantial seasonal variation in incidence confined to those over 5 years of age. Ascertainment is believed to be very complete, and is estimated to be $97.6 \%$ (95\% confidence interval $97.2 \%$ to $98.1 \%)$.

Key words: Type 1 (insulin-dependent) diabetes mellitus, epidemiology, aetiology, disease registry, childhood, ascertainment estimates.
Type 1 (insulin-dependent) diabetes mellitus is an increasingly common disorder in many European populations [1, 2]. Neither the causes of the condition, nor the causes of the increased incidence are known. Although a genetic predisposition is clearly of great importance, direct epidemiological evidence from case-control studies $[3,4]$ and indirect epidemiological evidence from migrant studies $[5,6]$ indicate that environmental agents are also very important.

The descriptive epidemiology of Type 1 diabetes is an important source of information for the framing of aetiological hypotheses. Several prominent features require explanation. There is great geographical variation in incidence, with as much as a 40 -fold variation between countries; Finland and Sardinia have the highest incidence rates (over 30 per 100,000 per year); Japan, Africa and Korea have the lowest ( 0.3 to 2.5 per 100,000 per year) [7-13]. The age incidence curve typically shows a peak in early adolescence, and may have a secondary peak earlier in childhood. There is marked seasonality of onset in many (though not all) studies [12,14-17], although this may relate more to infections precipitating a metabolic decompensation in prediabetic persons, than to any aetiological agent [8]. The incidence in a population may change rapidly during short periods of time, whether in the indigenous population [18], or in migrant populations [5].
A necessary first step in any series of investigations of the aetiology of Type 1 diabetes is to establish a good, well-validated register. This was the aim of the Yorkshire project.

\section{Subjects, materials and methods}

\section{Subjects}

A register of all diabetic children diagnosed while living in the Yorkshire Regional Health Authority (West Yorkshire, North Yorkshire and Humberside) in the United Kingdom was established in 1989. The Regional Health Authority had an average resident population of 840,000 persons under the age of 17 years during the period of this study.

Children newly diagnosed, satisfying standard criteria for the diagnosis of Type 1 diabetes, were recorded retrospectively back to 1978, and prospectively from 1989 onwards. All children diagnosed while aged under 17 years, and usually resident in the region at the time of diagnosis were eligible. Children with cystic fibrosis (five subjects), or who had undergone a pancreatectomy (one subject) were excluded.

Subjects were ascertained from three independent sources. First, all of the diabetologists and paediatricians in the region were approached, and all agreed to participate. Subjects were ascertained from their clinic records, and from the records of diabetic nurse specialists attached to the clinics. Secondly, all of the general practition- 
Table 1. Numbers of cases identified through each method. Hospital indicates cases found in a search of hospital and clinic records; GP survey indicates cases found during a postal survey of general practitioners in Yorkshire; Tape indicates cases identified from a Hospital Activity Analysis computer tape

\begin{tabular}{lllr}
\hline Hospital & Tape & GP survey & \\
\cline { 3 - 4 } & & No & Yes \\
\hline No & No & $?$ & 45 \\
\multirow{3}{*}{ Yes } & Yes & 118 & 108 \\
& No & 44 & 59 \\
& Yes & 481 & 635 \\
\hline
\end{tabular}

Table 2. Results of the best fitting log-linear model for estimating the completeness of ascertainment by time period

\begin{tabular}{lccc}
\hline \multirow{3}{*}{$\begin{array}{l}\text { Estimated completeness of ascertainment } \\
\text { Time period }\end{array}$} & Estimate & \multicolumn{2}{l}{$9 \%$ Confidence limits } \\
\cline { 2 - 4 } & & Lower & Upper \\
\hline $1978-1980$ & $98.8 \%$ & $98.1 \%$ & $99.6 \%$ \\
$1981-1983$ & $96.4 \%$ & $92.9 \%$ & $99.7 \%$ \\
$1984-1986$ & $98.8 \%$ & $97.7 \%$ & $99.8 \%$ \\
$1987-1990$ & $97.1 \%$ & $95.6 \%$ & $98.4 \%$ \\
$1978-1990$ & $97.7 \%$ & $97.2 \%$ & $98.1 \%$ \\
\hline
\end{tabular}

Table 3. Age-specific incidence of diabetes, per 100,000 persons per year, for males and females separately, and combined, in Yorkshire from 1978 to 1990 , standardised to the 1981 census population

\begin{tabular}{|c|c|c|c|c|c|c|}
\hline \multirow{2}{*}{$\begin{array}{l}\text { Age } \\
\text { (years) }\end{array}$} & \multicolumn{2}{|c|}{ Male } & \multicolumn{2}{|c|}{ Female } & \multicolumn{2}{|c|}{ Combined } \\
\hline & $n$ & Rate & $n$ & Rate & $n$ & Rate \\
\hline $0-4$ & 149 & 9.8 & 139 & 9.6 & 288 & 9.7 \\
\hline $5-9$ & 210 & 13.1 & 204 & 13.4 & 414 & 13.3 \\
\hline $10-14$ & 320 & 18.2 & 283 & 16.9 & 603 & 17.6 \\
\hline $15-16$ & 119 & 16.4 & 60 & 8.7 & 179 & 12.6 \\
\hline
\end{tabular}

Table 4. Overall incidence per 100,000 persons per year reported from other studies in the United Kingdom

\begin{tabular}{llll}
\hline Study & Year of study & Age (years) & Incidence \\
\hline Yorkshire $^{\mathrm{a}}$ & $1978-1990$ & $0-16$ & 13.6 \\
Oxford 1 [29] & $1985-1986$ & $0-20$ & 15.6 \\
Oxford 2 [10] & $1989-1990$ & $0-14$ & 16.4 \\
British Isles [41] & 1988 & $0-14$ & 13.5 \\
Scotland [28] & $1977-1983$ & $0-18$ & 21.0 \\
\hline
\end{tabular}

${ }^{a}$ Present study

Table 5. Standardised incidence ratios (SIR) by county of residence at diagnosis. The reference is the entire series

\begin{tabular}{lcrcc}
\hline County & Cases & SIR & $\begin{array}{l}\text { 95\% Confidence } \\
\text { interval }\end{array}$ & $p$ value \\
\hline West Yorkshire & 755 & 87.2 & $81.0-93.4$ & $<0.001$ \\
Humberside & 438 & 121.2 & $109.8-132.5$ & $<0.001$ \\
North Yorkshire & 291 & 113.3 & $100.2-126.3$ & 0.04 \\
\hline
\end{tabular}

Significance test for between-county heterogeneity: $p<0.0001$ $\left(\chi^{2}=34.29\right.$ on $\left.2 d f\right)$

ers in the region were asked (by post) to provide a list of all known patients with diabetes, diagnosed under the age of 17 years, on their practice lists. One reminder letter was sent to those who did not reply within 4 weeks. Thirdly, a list of all admissions to hospitals in the Yorkshire region from 1969 to 1992 , where a discharge diagnosis of
Table 6. Results of the age-period-cohort analysis. The best fitting model (with a Poisson error distribution, a logarithmic link function and the logarithm of the person-years at risk in each cell as an offset variable) had main effects for age, sex, county of residence, a drift term, a non-linear period term, and an age by sex interaction. The residual deviance after fitting was 96.44 on $83 d f$

\begin{tabular}{lll}
\hline Baseline rate & \multicolumn{2}{l}{7.35 per 100,000 per year $^{\mathrm{a}}$} \\
\cline { 2 - 3 } Effect & Rate Ratio & $\begin{array}{l}95 \% \text { Confidence } \\
\text { interval }\end{array}$ \\
\hline Age group 1 & 1.00 & $-^{\mathrm{b}}$ \\
Age group 2 & 1.37 & $0.08,1.74$ \\
Age group 3 & 1.82 & $1.45,2.26$ \\
Age group 4 & 2.38 & $1.91,2.95$ \\
West Yorkshire & 1.00 & $-^{\mathrm{b}}$ \\
North Yorkshire & 1.28 & $1.12,1.47$ \\
Humberside & 1.39 & $1.23,1.56$ \\
Male & 1.00 & $-^{\mathrm{b}}$ \\
Female & 0.96 & $0.74,1.25$ \\
Linear drift (per period) & 1.06 & $1.01,1.11$ \\
Non-linear period 1 & 1.00 & $-^{\mathrm{b}}$ \\
Non-linear period 2 & 0.84 & $0.73,0.96$ \\
Non-linear period 3 & 0.95 & $0.83,1.07$ \\
Non-linear period 4 & 1.00 & $-^{\mathrm{b}}$ \\
Age group 1. Female & 1.00 & $-^{\mathrm{b}}$ \\
Age group 2. Female & 1.10 & $0.78,1.55$ \\
Age group 3. Female & 1.15 & $0.83,1.59$ \\
Age group 4. Female & 0.67 & $0.49,0.93$ \\
\hline Age & &
\end{tabular}

Age group $1,0-4.25$ years; $2,4.2-8.5$ years; $3,8.5-12.75$ years; 4 , 12.75-under 17 years.

Period 1, 1 January 1978-31 March 1981; 2, 1 April 1981-30 June 1984; 3, 1 July 1984-30 September $1987 ; 4$, 1 October 1987-31 December 1990

${ }^{a}$ Baseline is males aged 0 to 4.25 years, diagnosed between 1 January 1978 and 31 March 1981, and resident in West Yorkshire. All rate ratios are calculated relative to this baseline.

${ }^{\mathrm{b}}$ These rate ratios are constrained to be equal to $1 \mathrm{by}$ the model.

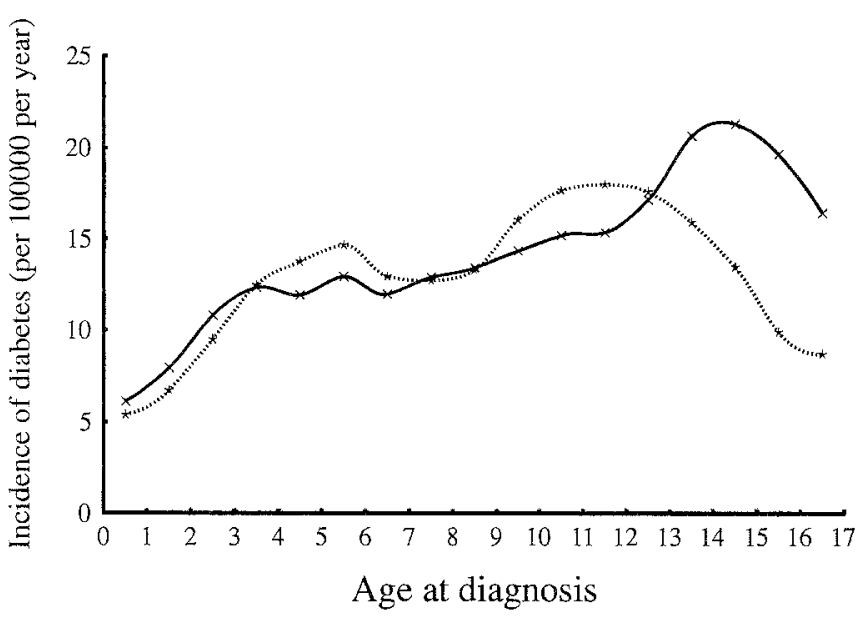

Fig. 1. Age-specific incidence of diabetes by single year of age from 1978 to 1990 . Smoothed using a 3 year moving average. Males $\times-$, females *-.-

diabetes (International Classification of Disease 250) was recorded for a person aged under 17 years, was obtained from the Yorkshire Regional Health Authority.

For each subject identified from any one of these sources the hospital notes were obtained. Following a structured abstraction form, basic demographic data were recorded from the notes. The child's name, sex, address at diagnosis, postcode at diagnosis, date of birth, 
date of diagnosis, presenting symptoms, and family history of diabetes were noted. Where a set of notes recorded only follow-up details on a patient, the original notes from the time of diagnosis were obtained.

\section{Population estimates}

Those subjects recorded as having been diagnosed between 1978 and 1990 were allocated to 1981 counties and wards using the frozen version of the central postcode directory [19]. Census small area statistics were extracted from the records of the 1971, 1981 and 1991 censuses held at the Manchester Computing Centre using the SASPAC package [20]. Incidence rates were calculated with locally written software [21].

Population figures were derived for each single year by interpolation from the 1971 census (adjusted to 1974 boundaries), the 1981 census and the 1991 census. For the age-period-cohort analysis linear interpolation within age and sex groups was used to estimate the population for four periods of 3.25 years each.

\section{Statistical analysis}

Statistical analyses were performed using Genstat 5.1 [22]. Completeness of ascertainment was estimated using methods based on the capture-recapture technique, analysed using log-linear models [23]. This procedure enables one to test the independence of sources assumption of traditional methods. The age-period-cohort analysis used the method of Clayton and Schifflers [24,25]. This approach addresses the fundamental problem of the non-identifiability of separate age, period and cohort effects in a novel way. Instead of simply fitting period or cohort effects, these terms are broken down into a linear drift term, and non-linear period or cohort effects. Drift is a linear increase with time, which may be due to period effects, cohort effects, or a combination of both. Due to the identifiability problem it cannot be directly attributed to one or the other. Tests for seasonal variation in incidence were carried out using the method of Walter and Elwood [26].

\section{Results}

Between 1978 and 1990, 1,490 children were diagnosed as having Type 1 diabetes in Yorkshire. Of these 1,219 were identified through the hospital records, 847 through the postal survey of general practitioners, and 1,342 from the tape provided by the Regional Health Authority. A total of 635 subjects ( $43 \%$ ) were identified by all three methods (Table 1). The response rate to the postal survey was $67 \%$. The estimated completeness of ascertainment was $97.6 \%$ (95\% confidence interval (CI) $97.2 \%$ to $98.1 \%$ ). There was no evidence for any substantial variation in completeness of ascertainment over the period of the study (Table 2).

The incidence rate over the entire time period was 13.7 per 100,000 per year for ages 0 to 14 years, and 13.6 per 100,000 per year for ages 0 to 16 years (Table 3, Fig. 1). Results from other UK studies are shown in Table 4 for comparison. There are two peaks in incidence, at ages 4 to 6 , and at ages 10 to 15 . Girls have their peak incidence at age 10 , earlier than boys, whose peak incidence is at age 14 . The difference between the mean ages at onset for this peak (ages 8 to 16 years) was 0.64 of a year $(95 \% \mathrm{Cr} 0.34$ to 0.95 years). For children 7 years and under, the mean ages at onset for boys and girls were almost identical (dif-

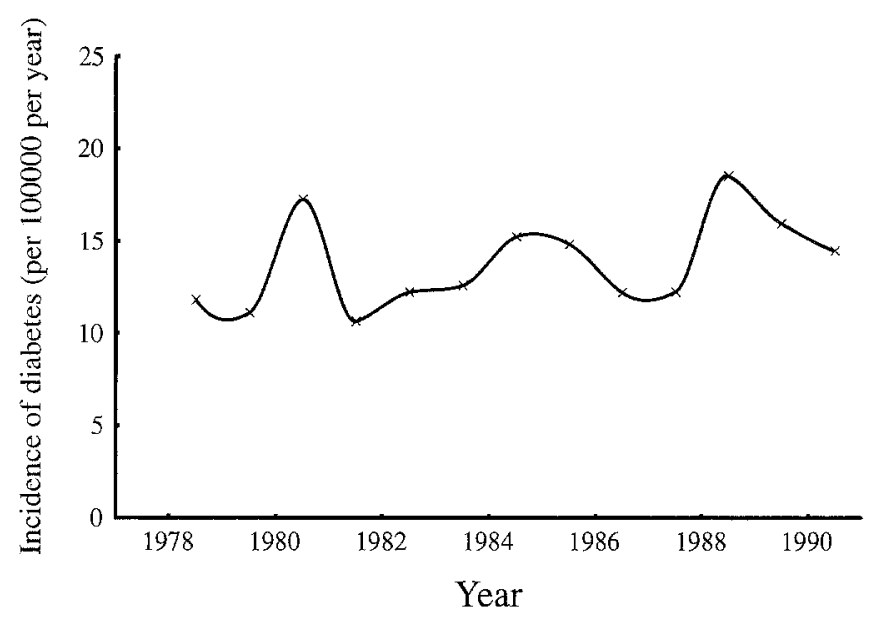

Fig. 2. A plot of the annual incidence of diabetes (per 100,000 persons per year), directly standardised to the 1981 census population, in Yorkshire from 1978 to 1990 inclusive

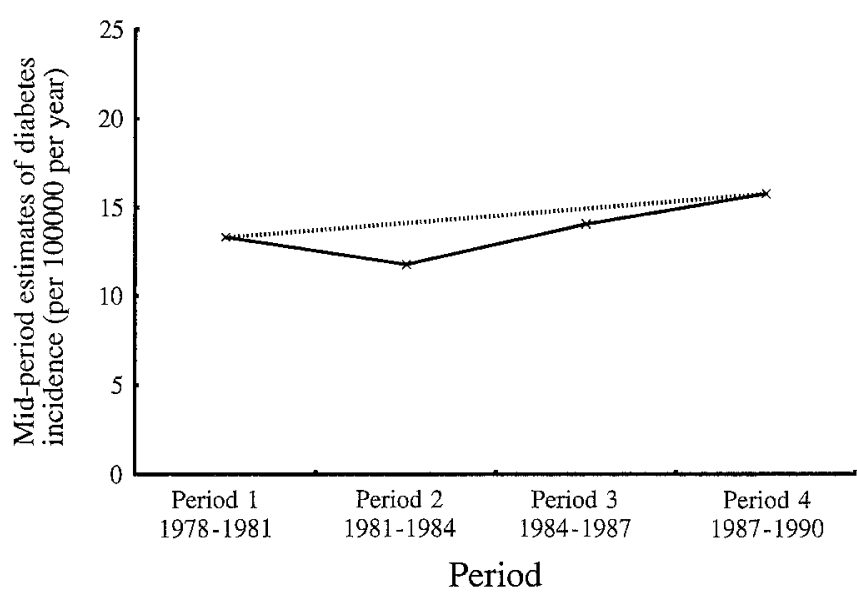

Fig. 3. The estimated change in diabetes incidence over the study period (i.e. the drift), and estimates of mid-period diabetes incidence from the ageperiod-cohort model. Drift effect $\cdots$, fitted incidence $x-$

ference 0.14 years; $95 \% \mathrm{CI}-0.4$ to 0.2 years). There is a marked variation in incidence between the three counties, with West Yorkshire having the lowest incidence, and Humberside the highest (Table 5).

Figure 2 shows the changes in diabetes incidence during the 13 years from 1978 to 1990 . For further analysis four equal age groups, four equal periods, and seven approximate birth cohorts were calculated from the individual records (Table 6). An age-period-cohort analysis was performed. The best fitting model was that which included main effects for age, sex and county, an age by sex interaction term, a drift term, and a non-linear period effect (Table 6). The regular drift effect suggests an increase in incidence from 1978 to 1990 of $1.75 \%$ a year $(95 \% \mathrm{CI} 0.28 \%$ to $3.25 \%$ ). At this rate the incidence would double in 40 years. The predictions from this model for the middle of each period, and the drift effect are shown in Figure 3. Inspection of the incidence by single years suggests a cyclical pattern with a period of 4 years (Fig.2).

Marked seasonal variation in incidence was identified with peak incidence in winter $\left(\chi^{2}=48.24 ; d f=2\right.$; 


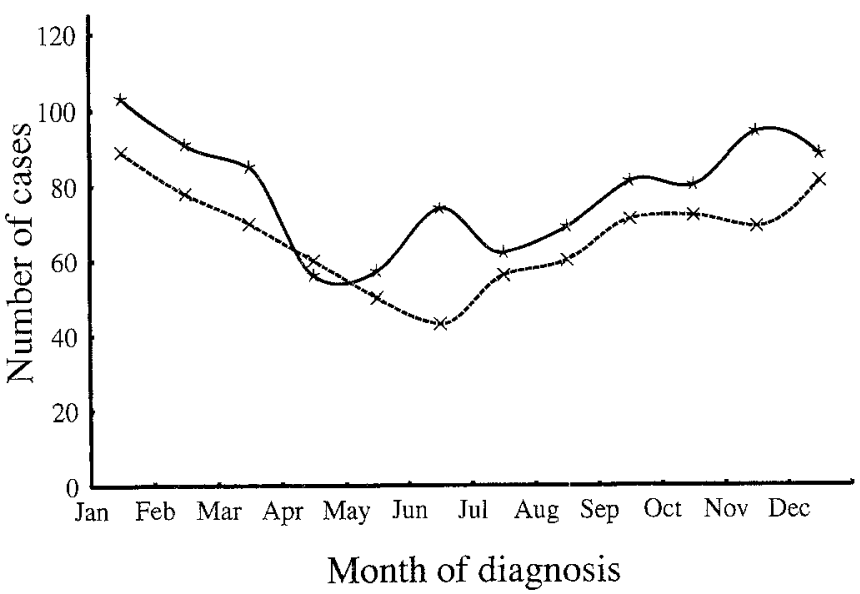

Fig.4. Diabetes incidence by month and sex showing the similar patterns of seasonal variation among males and females. Males *-, females $\times--$

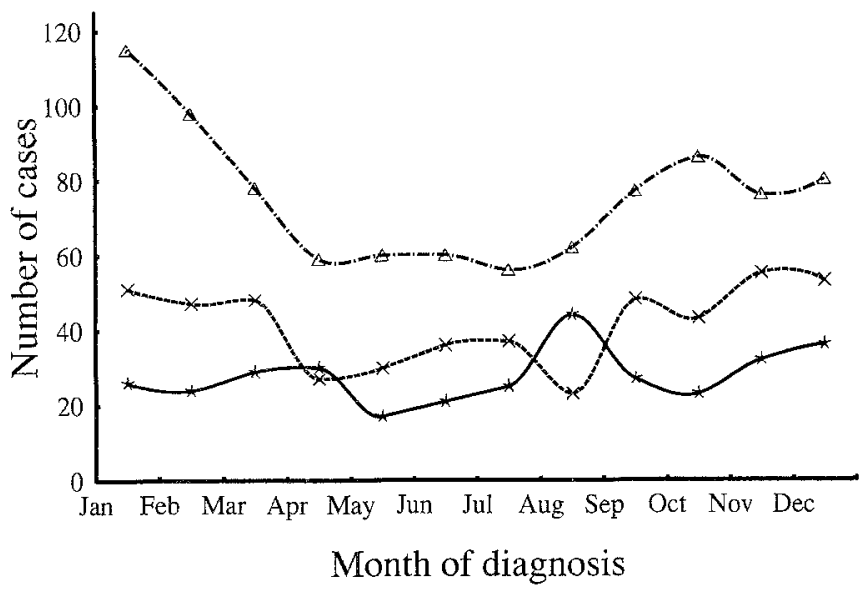

Fig.5. Diabetes incidence by month and age, showing the marked variation in the seasonality of occurrence by age. $0-4$ years $*-, 5-9$ years $\times$---, 10 years and older $\triangle \cdots \cdot$

$p<0.0001)$. There was no difference in the pattern of seasonal onset between boys and girls $\left(\chi^{2}=23.73\right.$; $d f=2$; $p<0.00001$ for boys; $\chi^{2}=25.34 ; d f=2 ; p<0.00001$ for girls) (Fig. 4). There was no seasonal variation among children under 5 years old $\left(\chi^{2}=3.21 ; d f=2 ; p=0.2\right)$, some seasonal variation among children aged between 5 and 9 $\left(\chi^{2}=21.11 ; d f=2 ; p=0.00002\right)$, and very marked variation in incidence in the oldest children, 10 to 16 years old, $\left(\chi^{2}=31.40 ; d f=2 ; p<0.00001\right)$ (Fig. 5$)$.

\section{Discussion}

Our results are broadly comparable to those from other European registries. Studies from Scotland [27, 28], which lies to the north of Yorkshire have reported substantially higher rates of diabetes than our study, while studies from Oxford $[10,29]$ which lies to the south have reported similar or slightly higher rates. This is consistent with a weak north-south gradient in incidence across the country, although more years of data from Oxford, and more recent data from Scotland would be required to confirm this.
The age-incidence curve is similar to that reported in other studies, both European [8, 30, 31] and Asian [12]. Boys have their peak incidence later than girls, presumably because they tend to enter puberty later than girls, and have a later pubertal growth spurt. This leads to an increased demand for insulin, and could cause a stressed pancreas to decompensate. There is modest evidence for a second peak in early childhood at 5 or 6 years of age.

The pattern of seasonality is similar to that reported in many other studies $[8,12,14,31-35]$ with excess incidence in the local winter. Some studies have not shown this $[17$, 36]. There is no seasonal variation in the youngest children, and the variation is most marked in the oldest children. This variation may reflect differing levels of exposure to infectious disease, leading to a different temporal pattern of metabolic stress triggering the clinical manifestations of ketoacidosis $[8,17]$. Some studies have reported more seasonal variation in boys, than in girls, $[8,33]$ but we found no noticeable difference.

Our study confirms the general experience of registers in the United Kingdom such as those from Leicester [37] which showed a steady increase in incidence from 1950 to 1980; and with studies from Scotland [27, 28] which showed an increasing incidence from 1968 to 1983. Ascertainment in Leicester is believed to be very high [37], and while the methods used by Patterson et al. [28] have been criticised [2,38], other studies from Scotland [39] tend to confirm their findings. Comparison of the two British national surveys of diabetes [40,41] is difficult as the degree of ascertainment in the first study was unknown, and was probably low. Hence the apparent doubling in incidence between these two studies is probably artefactual.

Studies from continental Europe, reviewed by Bingley and Gale [2] suggested that an increasing incidence was a continent-wide event. Tuomilehto et al. [42] confirmed evidence of further increase from Finland, as did Joner and Søvik [31] from Norway, and Nystrom et al. [43] from Sweden. Studies from the United States and Canada have shown either no evidence of an increase over time, or evidence for a very limited increase $[15,44]$. The most extensive study yet conducted of temporal trends in incidence [1] confirms this pattern, significant increases from 2.6 to $12.2 \%$ per year, in Europe, Japan and New Zealand, but no consistent increase from North America. Our incidence is increasing more slowly than most other areas studied, at $1.75 \%$ per year.

Our temporal incidence curve was complex, with three clearly-defined peaks, at approximately 4-year intervals, in 1980, 1984-1985 and 1988. The pattern was similar for all age groups. Peaks in incidence in 1982 or 1983 and 1986 have been identified in several registries in Northern Europe $[13,18,42,43,45,46]$, suggesting that there may be large scale patterns in diabetes incidence.

The pattern of cyclical variation in temporal incidence found in our study and others is of great interest. Relatively few environmental variables fluctuate periodically with periods of more than 1 year. Clearly certain economic series behave in this way, and so social causes cannot be excluded. However, infectious diseases also behave in this way, often showing very marked periodicity [47]. One study [48] has linked cyclical variation in diabetes in- 
cidence to cyclical variation in reported infections with the mumps virus, although other studies have not reported this [49]. Several other registries have published temporal incidence curves showing multiple peaks in incidence $[1,13,18,42,43,46]$, although this is not a universal feature [1]. Clearly short-term variations in incidence are a feature of diabetes epidemiology, a fact which complicates the interpretation of apparent epidemics of the disease.

More speculatively, given the limitations of the existing evidence, one could suggest that these peaks, occurring at different times in different places, may be markers for the continent-wide spread of some infectious agent. Epidemic waves with a very large scale have been identified for many infectious diseases, particularly influenza, plague and cholera [50,51]. New methods are being developed to study the movements of infections over very large areas [52]. If large scale patterns of this kind can be identified, the implications for theories of the aetiology of diabetes would be substantial.

Further work on these questions will require international collaborative studies. These should be directed towards filling gaps in the areas covered by existing registries, and preparing for transnational analyses of disease variation, on a variety of spatial scales, and over time.

Acknowledgements. This study, and CS and HEBL, were funded by a locally organised research grant from the Yorkshire Regional Health Authority (Ref LW 219). AS, RJMcN and RAC are funded by the Leukaemia Research Fund. We thank our colleagues in the Yorkshire region for allowing us to study their patients, and Dr. P.A.McKinney and Dr. F.E. Alexander for their advice, and support. We thank Mr. K. Fitzpatrick and Mr. M. Lawrie for providing hospital activity analysis tapes and computing support, respectively. We thank the referees, and the associate editor for their helpful and constructive comments.

\section{References}

1. Diabetes epidemiology research international (1990) Secular trends in incidence of childhood IDDM in 10 countries. Diabetes 39: 858-864

2. Bingley PJ, Gale EAM (1989) Rising incidence of IDDM in Europe. Diabetes Care 12: 289-295

3. Dahlquist G, Blom L, Lönnberg G (1991) The Swedish Childhood Diabetes Study - a multivariate analysis of risk determinants for diabetes in different age groups. Diabetologia 34: 757762

4. Dahlquist G, Källén B (1992) Maternal-child blood group incompatibility and other perinatal events increase the risk for early-onset type 1 (insulin-dependent) diabetes mellitus. Diabetologia 35: 671-675

5. Bodansky HJ, Staines A, Stephenson C, Haigh D, Cartwright RA (1992) Evidence for an environmental effect in the aetiology of insulin dependent diabetes in a transmigratory population. BMJ 304: 1020-1022

6. Cohen T (1979) Juvenile diabetes mellitus. Isr J Med Sci 15: 1009-1010

7. Reunanen A, Åkerblom HK, Kaar M (1982) Prevalence and tenyear incidence of diabetes mellitus in children and adolescents in Finland. Acta Paediatrica Scand 71: 893-899

8. Dahlquist G, Blom L, Holmgren G et al. (1985) The epidemiology of diabetes in Swedish children 0-14 years - a six-year prospective study. Diabetologia 28: 802-808
9. Diabetes epidemiology research international (1987) Preventing insulin dependent diabetes mellitus: the environmental challenge. BMJ 295: 479-481

10. Green A, Gale EAM, Patterson CC (1992) Incidence of childhood onset insulin-dependent diabetes mellitus: the Eurodiab ACE study. Lancet 339: 905-909

11. Swai ABM, Lutale JB, McLarty DG (1993) Prospective study over 10 years of the incidence of diabetes mellitus in Dar es Salaam. Tanzania. BMJ 306: 1570-1572

12. Matsuura N, Fukushima N, Fujita H et al. (1983) Epidemiological survey of juvenile-onset insulin dependent diabetes mellitus (IDDM) in Hokkaido, Japan, 1973-1981 Tohoku J Exp Med 141 [Suppl]: 181-189

13. Tuomilehto J, Podar T, Brigis $\mathrm{G}$ et al. (1992) Comparison of the incidence of insulin-dependent diabetes mellitus in childhood among five Baltic populations during 1983-1988. Int J Epidemiol 21:518-532

14. Scott RS, Brown LJ, Darlow BA, Forbes LV, Moore MP (1992) Temporal variation in incidence of IDDM in Canterbury, New Zealand. Diabetes Care 15: 895-899

15. Siematickyi J, Colle E, Aubert D, Campbell S, Belmonte M (1986) The distribution of type 1 (insulin-dependent) diabetes mellitus by age, sex, secular trend, seasonality, time clusters and space-time clusters: evidence from Montreal, 1971-1983. Am J Epidemiol 124: 545-559

16. Sutton DL, Lyle DM, Pierce JP (1989) Incidence and prevalence of insulin-dependent diabetes mellitus in the zero to 19 years' age-group in Sydney. Med J Australia 151: 140-146

17. Ludvigsson J, Afoke AO (1989) Seasonality of type 1 (insulindependent) diabetes mellitus: values of C-peptide, insulin antibodies and haemoglobin $\mathrm{A}_{1 \mathrm{c}}$ show evidence of a more rapid loss of insulin secretion in epidemic patients. Diabetologia 32: 84-91

18. Rewers M, LaPorte RE, Walczak M, Dmochowski K, Bogaczynska E (1987) Apparent epidemic of insulin-dependent diabetes mellitus in mid-western Poland. Diabetes 36: 106-113

19. Office of Population Censuses and Surveys (1989) Central postcode directory. Office of Population Censuses and Surveys, London

20. SASPAC consortium (1987) SASPAC users guide. Manchester Computing Centre, Manchester

21. Cartwright RA, Alexander FE, McKinney PA, Ricketts TJ (1990) Leukaemia and lymphoma, an atlas of distribution within areas of England and Wales 1984-1988. Leukaemia Research Fund, Leeds

22. Payne RW, Lane PW, Ainsley AE et al. (1987) Genstat 5 reference manual. Clarendon Press, Oxford

23. Hook EB, Regal RR (1982) Validity of Bernoulli census, loglinear, and truncated binomial models for correcting for underascertainment in prevalence studies. Am J Epidemiol 116: 168176

24. Clayton D, Schifflers E (1987) Models for temporal variation in cancer rates I: age-period and age-cohort models. Stat Med 6: 449-467

25. Clayton D, Schifflers E (1987) Models for temporal variation in cancer rates II: age-period-cohort models. Stat Med 6: 469-481

26. Walter SD, Elwood JM (1975) A test for seasonality of events with a variable population at risk. Br J Prev Soc Med 29: 18-21

27. Patterson CC, Thorogood M, Smith PG, Heasman MA, Clarke JA, Mann JI (1983) Epidemiology of type 1 (insulin-dependent) diabetes in Scotland 1968-1978: evidence of an increasing incidence. Diabetologia 24: 238-243

28. Patterson CC, Smith PG, Webb J, Heasman MA, Mann JI (1988) Geographical variation in the incidence of diabetes mellitus in Scottish children during the period 1977-1983. Diabetic Med 5: 160-165

29. Bingley PJ, Gale EAM (1989) Incidence of insulin dependent diabetes in England: a study in the Oxford region, 1985-6. BMJ 298: 558-560

30. Calori G, Gallus G, Garancini P, Repetto F, Micossi P (1990) Identification of the cohort of type 1 diabetic patients presenting 
in Lombardy in 1983-84: a validated assessment. Diabetic Med 7: $595-599$

31. Joner G, Søvik G (1989) Increasing incidence of diabetes mellitus in Norwegian children 0-14 years of age 1973-1982. Diabetologia 32: 79-83

32. Christau B, Kromann H, Andersen OO et al. (1977) Incidence, seasonal and geographical patterns of juvenile-onset insulin dependent diabetes mellitus in Denmark. Diabetologia 13:281-284

33. Gray RS, Duncan LJP, Clarke BF (1979) Seasonal onset of insulin-dependent diabetes in relation to sex and age at onset. Diabetologia 17: 29-32

34. Fishbein HA, LaPorte RE, Orchard TJ, Drash AL, Kuller LH, Wagener DK (1982) The Pittsburgh insulin-dependent diabetes mellitus registry: seasonal incidence. Diabetologia 23: 83-85

35. Lorenzi M, Cagliero E, Schmidt NJ (1985) Racial differences in incidence of juvenile-onset type 1 diabetes: epidemiologic studies in southern California. Diabetologia 28: 734-738

36. Tull ES, Roseman JR, Christian CLE (1991) Epidemiology of childhood diabetes mellitus in US Virgin Island from 1979 to 1988. Diabetes Care 14:558-564

37. Burden AC, Hearnshaw JR, Swift PGF (1989) Childhood diabetes mellitus: an increasing incidence. Diabetic Med 6: 334 336

38. Waugh NR (1986) Insulin-dependent diabetes in a Scottish region: incidence and urban-rural differences. J Epidemiol Comm Health 40: 240-243

39. Barclay RPC, Craig JO, Galloway CAS, Richardson JE, Shepherd RC, Smail PJ (1988) The incidence of childhood diabetes in certain parts of Scotland. Scottish Med J 33: 237-239

40. Bloom A, Hayes TM, Gamble DR (1975) Register of newly diagnosed diabetic children. BMJ (II): 580-583

41. Metcalfe MA, Baum JD (1991) Incidence of insulin dependent diabetes mellitus in children aged under 15 years in the British Isles during 1988. BMJ 302: 443-447

42. Tuomilehto J, Rewers M, Reunanen A et al. (1991) Increasing trend in type 1 (insulin-dependent) diabetes mellitus in childhood in Finland. Diabetologia 34: 282-287
43. Nystrom L, Dahlquist G, Rewers M, Wall S (1990) The Swedish childhood diabetes study: an analysis of the temporal variation in diabetes incidence 1978-1987. Int J Epidemiol 19: 141-146

44. Hamman RF, Gay EC, Cruickshanks KJ et al. (1990) Colorado IDDM registry. Incidence and validation of IDDM in children aged 0 to 17 yr. Diabetes Care 13: 499-506

45. Rewers M, LaPorte R, King H, Tuomilehto J (1988) Trends in the prevalence and incidence of diabetes: insulin dependent diabetes mellitus in childhood. World Health Stat Q 41: 179-189

46. Podar T, LaPorte RE, Tuomilehto J, Shubnikov E (1993) Risk of childhood type 1 diabetes for Russians in Estonia and Siberia. Int J Epidemiol 22: 262-267

47. Anderson R, May ER (1991) Dynamics of infectious disease in humans. Oxford University Press, Oxford

48. Sultz HA, Hart BA, Zielezny M, Schlesinger ER (1975) Is mumps virus an etiologic factor in juvenile diabetes mellitus? Pediatrics 86: 654-656

49. Fleegler FM, Rogers KD, Drash A, Rosenbloom AL, Travis LB, Court JM (1979) Age, sex and season of onset of juvenile diabetes in different geographic areas. Pediatrics 63: 374-379

50. Cliff AD, Haggett P (1988) Atlas of disease distributions. Blackwell, Oxford

51. Hope-Simpson E (1992) The transmission of epidemic influenza. Plenum Press, New York

52. Cliff AD, Haggett P, Stroup DF (1992) The geographic structure of measles epidemics in the Northeastern United States. Am J Epidemiol 136: 592-602

Received: 5 March 1993

and in revised form: 29 June 1993

Dr. A. Staines

LRF Unit for Clinical Epidemiology

17 Springfield Mount

Leeds LS2 9NG

UK 